\title{
Smartness and Strategic Priority Assessment in Transition to Mobility 4.0 for Smart Cities
}

\author{
Hakan İnaç ${ }^{1 *}$ (ID), Ercan Öztemel ${ }^{2}$ (iD), Mehmet Emin Aydın ${ }^{3}$ (iD \\ ${ }^{1}$ Marmara University, Institute of Pure and Applied Sciences, Department of Engineering Management, İstanbul/Turkey \\ ${ }^{2}$ Marmara University, Faculty of Engineering, Department of Industrial Engineering, İstanbul/Turkey \\ ${ }^{3}$ University of the West of England, Department of Computer Science and Creative Technologies, Bristol/UK \\ hkninac@gmail.com, eoztemel@marmara.edu.tr, mehmet.aydin@uwe.ac.uk
}

\begin{abstract}
Digital transformation of urban transportation services attracts significant attention within the scope of smart city studies. It is known as a strategic action with many investment opportunities for the future cities, therefore it attracts the attention of enterprises and institutions. A sound and sustainable digital transformation requires substantial decision support in order to customize the needs and priorities of cities, especially in developing countries, where a lack of knowledge and skills is the case. Mobility 4.0 is recognized as the most up-to-date state of art technology and vision for urban transportation in the age of smart cities. Mobility as a Service (MaAS) is one of the most prominent Mobility 4.0 components that needs to be developed with an integrated management approach, which is available for research and development investments that have defined conceptually yet. In this study, the smartness level of city transport services is identified with a four-level transition approach. The transition from Mobility 3.0 to Mobility 4.0 for cities has been carried out with conceptual integrated management design of MaAS and demonstrated with a case study. The study also adapted a series of new strategically targeted transformation priorities for cities with reference to research and development strategies.
\end{abstract}

Keywords: Digital Transformation, MaAS, Mobility 4.0, Transportation Management, Nominal Group Technique, Smart City.

\section{Akılı Şehirler İçin Mobilite 4.0 Geçişinde Akıllılık ve Stratejik Öncelik Değerlendirmesi}

\section{Öz}

Kentsel ulaşım hizmetlerinin dijital dönüşümü, akıllı şehir çalışmalarında öne çıkan ve büyük ilgi gören bir konudur. Bu dönüşüm geleceğin şehirleri için birçok yatırım firsatı içeren stratejik bir eylem olarak bilinir, bu nedenle şirketlerin ve kurumların ilgisini çekmektedir. Güçlü ve sürdürülebilir bir dijital dönüşüm, özellikle bilgi ve beceri eksikliğinin söz konusu olduğu gelişmekte olan ülkelerde, şehirlerin ihtiyaçlarını ve önceliklerini özelleştirmek için etkin bir karar desteği gerektirir. Mobilite 4.0, akıllı şehirler çağında kentsel ulaşım için en güncel teknoloji ve vizyon olarak kabul edilmektedir. Bir hizmet olarak hareketlilik (MaAS), kavramsal olarak henüz tanımlanmış araştırma ve geliştirme yatırımları için mevcut olan entegre bir yönetim yaklaşımıyla geliştirilmesi gereken en önemli Mobilite 4.0 bileşenlerinden biridir. Bu çalışmada, şehir içi ulaşım hizmetlerinin akıllılık seviyesi dört aşamalı bir geçiş yaklaşımı ile belirlenmiştir. Şehirler için Mobilite 3.0'dan Mobilite 4.0'a geçiş, MaAS'ın kavramsal entegre yönetim tasarımı ile örneklenmiş ve bir vaka çalışması ile gösterilmiştir. Çalışma da ayrıca, araştırma ve geliştirme stratejilerine referansla şehirler için stratejik olarak hedeflenmiş bir dizi yeni dönüşüm önceliği ile ilgili önerilerde bulunulmuştur.

Anahtar Kelimeler: Dijital Dönüşüm, MaAS, Mobilite 4.0, Ulaşım Yönetimi, Nominal Grup Tekniği, Akıllı Şehir. 


\section{Introduction}

Digital transformation is a crucial instrument of smart cities, which implies digitizing business processes using information and communication technologies (ICT) infrastructure, while a digital system supported by artificial intelligence technologies is known as an intelligent system. Emerging technologies help facilitate widespread use of smart services in urban life and city management, noting that use of smart systems is a transformation process that requires investment and takes time (Anttiroiko et al., 2014). In this regard, policy makers need to plan strategically focused transformation. It is known that credible assessment models are required to identify smartness level of digitalisation processes and to evaluate the efficiency, efficacy and sustainability of Intelligent Transport Systems (ITS).

Digital transformation is an ongoing process, which introduces new services while updating many existing services. Particularly, the new services are initiated in the conceptual level, either through definitions originate from use cases or from prototypes, which remains uncertain and risky in comparison to the mature and well-defined services. There are cities that decide to take initiative for investing in infrastructures required for various services as part of digital transformation, while there are many others which may not afford to exercise new developments due to imposed uncertainties and risks of digital services owing to various city-specific circumstances, such as budgets, knowhow etc. Some cities realize the digital transformation process with sustainable city-specific strategies by experimenting with prototypes of digital services with pilot applications. Others may choose a risk-free digital transformation strategy with certain services which already have defined infrastructure service requirements and related process. In this respect, the determination of digitalisation targets for transportation services and the choice of a digital transformation strategy compatible with cities are investigated within the scope of this study.

The digitalization of urban transport systems is addressed in the literature with the concepts of smart city and Mobility 4.0. There are a number of city indicators for smart city assessment. Using various combinations of these, it is possible to comment on the smart transformation of cities. The most important causes of emissions in the cities emerge from the transportation services (Colvile et al., 2001). Traffic congestion, lack of public transport capacity, and lack of infrastructure are the most frequently complained problems (Redman et al., 2013). According to studies conducted in European Union countries, fossil fuel consumption, which corresponds to $24 \%$ of total greenhouse gas emissions and $1 / 3$ of total energy consumption, originates from the transportation sector (Foltýnová et al., 2018).
Smart cities have been evaluated with a general maturity approach that implies situational analysis for current position and evaluations for the implementation of new technologies in the literature. The studies exploit weighted average method using indicators determined as smart city evaluation model (Tay et al., 2018). Being a smart city is not an objective, but a means to achieve a goal (Akpinar, 2019). The approaches presented with maturity models make an assessment of the current situation. However, these studies do not provide decision support as they do not set digital transformation targets for cities according to their potential.

On the other hand, the concept of Mobility 4.0 can be viewed as an implementation of Industry 4.0 to perform digital transformation of transportation services. The historical progress of Mobility 4.0 demonstrates how the stages of mobility develops alongside the emergence of smart city concepts, trends and smartness level. The development steps of the Mobility 4.0 are specified in terms of transportation services and utilized as a key performance indicator suggesting the level of smartness. We propose measurable objectives in determining the level of smartness specific to cities, rather than comparing the current level of digitalisation of cities with various criteria. This paper elaborates a digital transformation framework that takes into account the characteristics, capacities and specific strategies of cities based on expert opinion for decision makers responsible for the digital transformation of cities.

The proposed framework evaluates the digital transformation on component basis. The smartness level of each component is calculated by the model according to expert opinions utilising smart city indexes. Investments by local governments in research and development (R\&D) are needed for the digital transformation of conceptual services. Mobility as a service (MaAS) can be considered in this context. Additionally, in this study, the transition process of MaAS, which is conceptually defined only in literature, is analysed for different categorized cities with the transformation of digitization trends and Mobility 4.0 components. This approach assists to ascertain which city needs a priority of smartness transformation in terms of Mobility 4.0 components of MaAS first. A strategic evaluation is made according to the $R \& D$ investment potentials for the components under consideration and it is recommended to rank transformation priorities.

Expert views suggest that a healthier digital transformation process requires starting form strategic level, where the common strategies of cities with respect to the digital transformation of transportation services are developed with leading, sustainable and costefficient integral systems. For a sustainable ecosystem, it is necessary to reduce the use of private transportation offering comfortable and highly capacitated public transportation and increase mobility, while, for a habitable environment, cities should prioritise 
accessible, comfortable, transparent and economical transportation services that prevent noise and noise pollution.

The framework introduced in this work evaluates the qualities and potentials of cities imposes working principles to be considered as a road map. The following contributions are introduced by this article:

(1) The concept of Mobility 4.0 is summarized with its components, explained with its historical development, user trends and the level of smartness in digitization. This is useful to grasp the essences of the digital transformation of cities in transportation services.

(2) An integrated management approach associated with Mobility as a service (MaAS) in this respect is considered based on R\&D investment decisions, which is required for smart transportation platforms and structural transformation.

(3) The concept of the level of smartness in transportation systems is presented. It proposes a fourstage transformation model for digital transformation defining a 4-tier operation and management process to evaluate integrated components.

(4) The general flowchart/road map of the proposed approach is included.

(5) The strategically focused prioritization approach is explained and exemplified.

(6) The implementation is comparatively evaluated.

\section{Literature Review and Background}

Modern transportation faces prominent challenges such as congestion, pollution, greenhouse gas emissions, the scarcity of oil, growing last mile inefficiency in increasing a city's density, growing transport demand, which appear to impose causal effects upon increasing inefficiency in the transportation systems. Therefore, it enforces the policymakers and industrial leads to address these issues for sustainability concerns (Müller and Liedtke). The use of advanced technology and systematic management approach will increase efficiency and reduce pressure in the use of limited resources. The main strategy to be implemented in the solution of transportation-related city problems is to design people-oriented, sustainable and liveable/habitable systems (Angelidou et al., 2018). Smart cities provide opportunities to use integrated service management and common infrastructure (Razaghi and Finger, 2018).

Mobility 4.0 concept is defined as "Integrated Urban Mobility", which aims to provide effective transport services by integrating all kind of emerging technologies in transportation (Sochor et al., 2015, Smith et al., 2018). Private and public sector cooperation (İnaç and Dönmez, 2018), mobile data collection (Şentürk and Coulibally, 2020), use of cloud technology (Cottrill, 2020) and artificial intelligence supported service systems are prioritised in the digital transformation of transportation systems components. There is no "one size fits all" Mobility 4.0 and it is critical to consider local specifications for successful implementation (Butler et al., 2020).

It is not trivial to identify the smartness level of smart cities since there are many elements and dimensions that characterize a smart city. It is equally difficult to define and propose a universal standard approach to reach an assessment level with the characteristics of cities around the world. That suggests that smart city assessments should take into account that cities have different visions and priorities to achieve their goals (Albino et al., 2015).

The following studies relevant to transportation components have mainly been carried out on transformation, which can be considered related to intelligent transportation systems. The studies and the components help determine the needs for a general framework of digital transformation.

$\checkmark$ Traffic jam (Mouchili et al., 2018)

$\checkmark$ Lack of parking lots (Ma and Xue, 2020)

$\checkmark$ Accessibility (Mouchili et al., 2018)

$\checkmark$ Traffic Safety (Mouchili et al., 2018)

$\checkmark$ Comfort problems (Lytras and Visvizi, 2018)

$\checkmark$ Noise pollution (Bello et al., 2019)

$\checkmark$ Visual pollution (Bello et al., 2019)

$\checkmark$ Air pollution (Kumar et al., 2015)

$\checkmark$ Limited public transportation capacity (Lytras and Visvizi, 2018)

$\checkmark$ Logistics distribution problems (Crainic et al., 2009, Yaman and Bayğın, 2020).

Many problems are linked by cause and effect relationship. Therefore, it is necessary to develop integrated approaches. A model containing expert opinion that evaluates the digital transformation needs of transportation components together has been developed in this study.

Essentially, there is no definitive approach to the measurement of smart city outcomes, although approaches should be using current indexes and their values for build a framework. The indices help simplifying the work of the engineers of the national and local authorities without requiring general knowledge of the subject and marketing the results to the public opinion with possible policy implementations.

The suggested indexes in the evaluation of the digitalization of transportation are as follows: Traffic Efficiency, Mobility, Traffic Safety, Pollution and Public Transportation Capacity (Kaparias et al., 2011).

The capabilities of cities, the structure of the city, its geographical conditions and the socio-economic structure of the region will naturally affect the digitalization goals. Indices suitable for these qualifications should be added to the evaluation criteria.

Four different development methods were used in the selection of smart city evaluation indicators. First, developers often choose peer-reviewed literature to choose smart city sizes and their indicators are weighting of composite indexes (Pringle, 2011). The second is rational expert opinions, using a combination of interrogative surveys, consultation workshops, the Delphi method and the Analytical Hierarchy Process 
(AHP) (Giffinger et al., 2007). Thirdly, it relies on the eco-design approach to involve various stakeholder groups (Manville et al., 2014). Fourth and finally, the best practices of smart city assessment are evaluated. Figure 1 shows which methodology is often used in such studies (Sharifi, 2020).

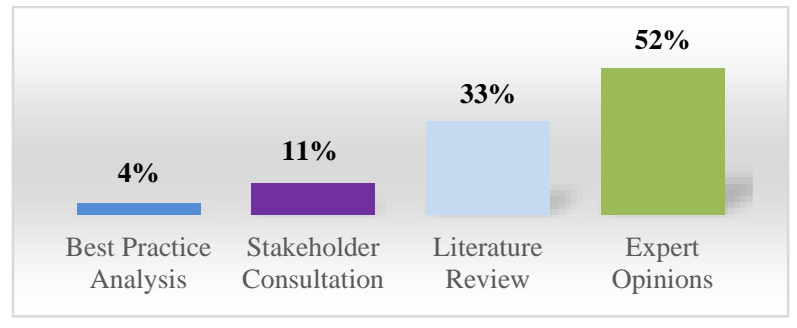

Figure 1. Major methods for development of assessment digital transformation (Sharifi, 2020).

Cities are classified into specific clusters for comparison with respect to various criteria such as economic development level, population, geographical location, ICT infrastructure. The most common classification criterion used is the economic development level of the countries. In this classification, cities are classified as developed country cities, developing countries cities and cities in underdeveloped countries (Kemeny and Storper, 2015). Another classification is done with population. For example, cities with a population of over 10 million are called megacities, while others are ranked as super city, middle city and small city (Ngo et al., 2019). Geographical location suggests that cities are classified as European cities, Far East cities, South American cities, African cities (Nagy, 2016). Meanwhile, in order to identify innovation and creativity level of countries, a classification has been made for countries according to the number of patent applications (Khayyat and Lee, 2015). We adopted a hybrid approach, in this study, to classify the cities using existing criteria in which the economic power, infrastructure opportunities, innovation provision and the impact of the population are taken into account.

The hybrid approach proposed in this study is inspired of research and development (R\&D) activities to adapt of new technologies. The idea is to consider smart city digital transformations process the same as the new product $R \& D$ strategies that are widely accepted in production and service systems. Companies in existing new product strategies; Classified by "First-tomarket", "Follow-the-leader" and "Me-too" strategies. (Morse et al., 2014). Likewise, cities can be categorised into such three classes with respect to their economic strength, innovation potential, and human resources. While cities are setting their strategic objectives are recommended to follow similar strategies;

$\checkmark$ "First-to-market" class can be reserved for cities with high innovation potential in developed countries with a population of over 10 million, such as London, Seoul, and New
York. In this study, this group of cities are referred to as "Leading City" that have $R \& D$ investment capabilities and are able to invest in digitalisation-wise future-oriented services defined as concepts. Cities in this group have $\mathrm{R} \& \mathrm{D}$ investment potential.

$\checkmark$ "Follow-the-leader" class of cities have lower population and high potential such as Amsterdam and Barcelona. In this study, they are referred to as "Sustainable City" that are classified as the cities capable of investing in prototype development for products and are following sustainable strategies for digital transformation with exercising through pilot applications.

$\checkmark$ Cities, such as Istanbul and Moscow, with high potential but limited economic power are defined to be in "Me-too" group. In this study, this group of cities are referred to as "Cost-efficient City". They transform developed and accepted digital services in cities.

This paper introduces the use a 4-tier model developed in the assessment of the smartness level based on expert opinion. It has been suggested to choose indexes used in smart city evaluations as indicators. The process flow diagram of the proposed model is presented in Figure 5.

Digitalisation offers substantial benefits to effectively manage infrastructure resources for the solution of transportation problems in the city life but takes a long time. Expert judgments and an implementation model are needed to decide which transport component should primarily be digitalised. The economic power and ICT capacities of the cities also need to be evaluated, as transformation decisions require new investment.

\section{Proposed Approach for Digital Transformation}

Similar to the digital transformation of transportation in many ways, it is associated with a widely used industrial concepts such as Industry 4.0.

Industry 4.0 is the most up-to-date version of industrial periods, which requires to understand its difference from previous industrial periods. The main technology of Industry 4.0 is the Cyber-Physical System (CPS), which is defined as the combination of physical and cybernetic systems (Lee et al., 2015, Klingenberg and Antunes, 2017). It is due to some important technical advances in Cyber-Physical Systems, the Internet, embedded systems, computer science and artificial intelligence (Hellinger and Seeger, 2011).

\subsection{Transition of Mobility 4.0}

The transformation of transportation services has been conducted with emerging technologies and 
innovations in-line with the development of the industry. The new version of mobility, also known as the new generation, is called "Mobility 4.0". At the time of traditional transport, the trends consisted of road transport by private vehicles and public transport travel by intercity railways. In recent times, multimodal transport services have developed with public-private cooperation. Nowadays, Mobility 4.0 allows the use of advanced technologies for efficient management of transport resources. With the concept of Mobility 4.0, the new trend of transportation management is to increase the sharing economy and mobility. The development of mobility and the concept of Mobility " 4.0 " is presented in Figure 2.

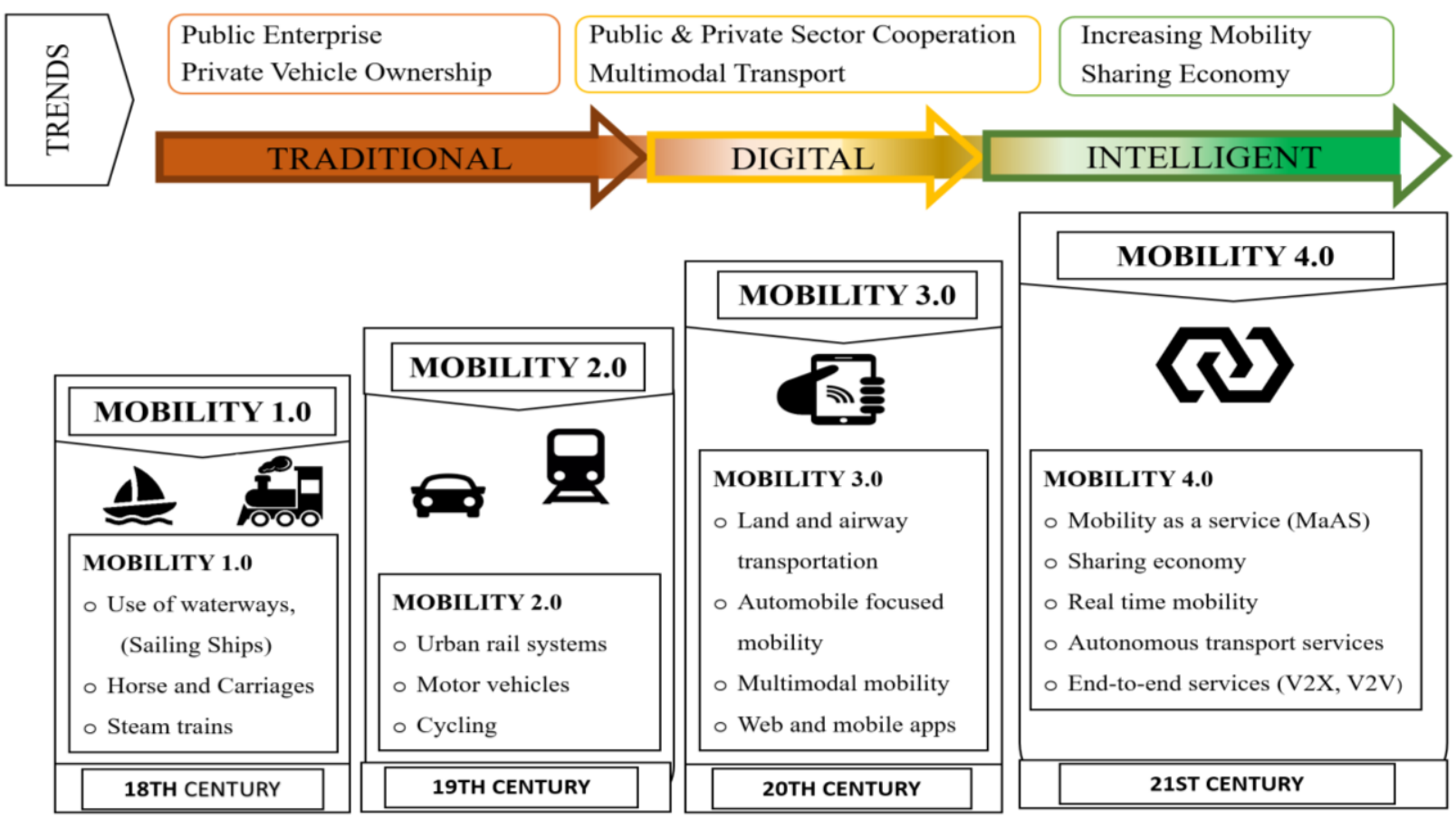

Figure 2. Development of transportation and the concept of Mobility 4.0

Until the end of the 18th century, in the first period of the industry, waterways and sailing ships were used in water transport. In this period, rail transport with steam-powered trains had begun to develop. On the land, horse and horse drawn carriages were used for transportation. Transportation services also changed with the invention of fossil fuel engines in the 19th century. In 1863 the word's first underground railway was opened in London (Halliday, 2013). Bicycles, automobiles, rail systems and maritime transport began to be widely used. These developments and the emerging transportation services until the 20th century are named as the traditional period in this article. Of course, these services constitute the basis of transportation components today. Some transportation components, which are considered to have no need for digital transformation, are expected to serve with traditional management.

In the 20th century, with the 3rd Industrial Revolution, electro mechanics and computer technologies appeared. In this period, land, water, rail and air transportation services developed. In the last years of this period, web-based systems started to be offered in transportation services. The use of electronic ticket systems and web services transportation services has also become widespread. Huge data has begun to be collected for mobile network usage and mobile applications and mobility. Digital services started to be used widely.

In the 21st century, stakeholders' expectations from transportation services have changed with the concepts of Smart city and Industry 4.0. An integrated management approach has been adopted in order to meet the conflicting expectations of the citizens, private sector and state administrations. This period, which is adopted as the Mobility 4.0 phase, covering today and the near future, is called the period of intelligent transportation systems in the study. In the period of Mobility 4.0; cyber physical system components such as artificial intelligence, big data and internet of things are expected to be widely used in transportation services. This period adopts the use of integrated transportation systems in the proposed model approach.

\subsection{Components of Mobility 4.0}

It is expected that many existing services will change in terms of standards and qualification with the digital 
transformation of transportation systems. In this context, digital transformation should propose a re-organization that includes new components in service management. It is recommended to make a transformation assessment with these new components created by digital integrated management.
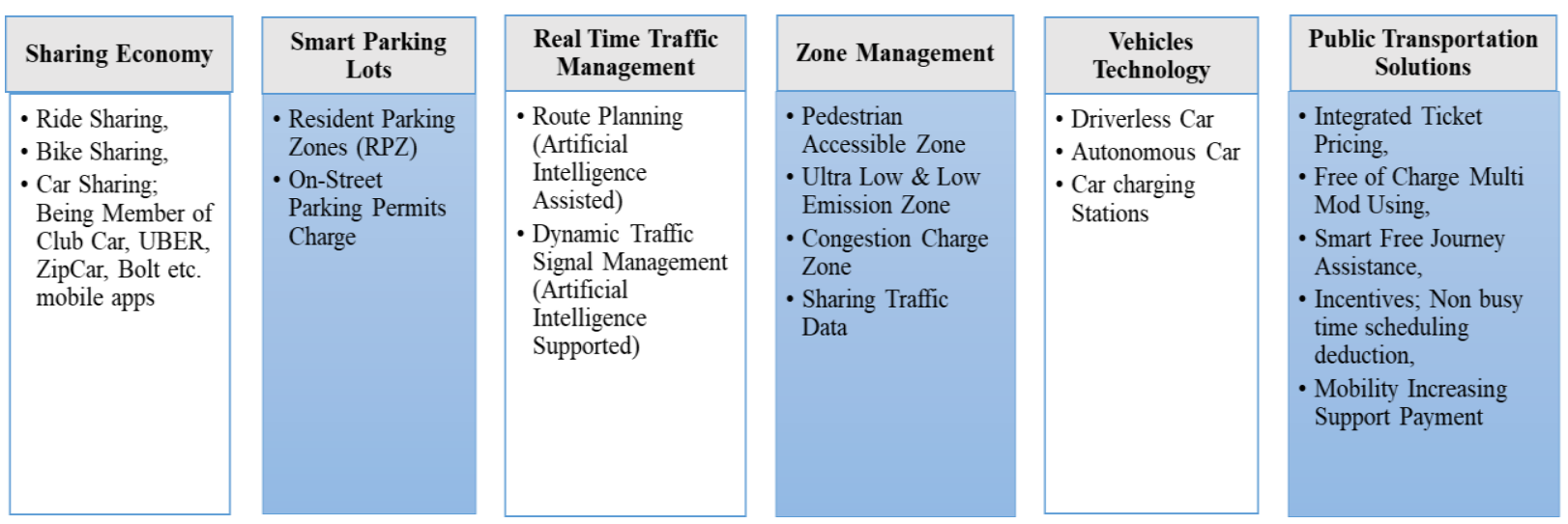

Figure 3. Components of Mobility $4.0 \&$ integrated transportation management

Expectations from transportation services; is changing with the developing technology and the digital world. In the near future, individual car ownership will be replaced by car-sharing economy systems. The diffusion of shared transportation can significantly change the vehicle ownership rate: each car sharing vehicle is estimated to remove 9 to 13 vehicles from the roads (Greenblatt and Shaheen, 2015), as most private cars are used less than $10 \%$ of the time (Fagnant and Kockelman, 2014). It is an accepted practice in developed countries that cities are restricted as low emission zones and only vehicles with reduced emission will be allowed access (Wolff and Perry, 2010). Due to the restricted parking lot and traffic congestion, demand suppression policies are implemented with the congestion charging for private vehicles (Metz, 2018).

Given the demand for daily and hourly limited city parking, lots must be suppressed. Cities like London are a thriving commercial and residential area consequently parking controls are necessary to maintain traffic flow and protect public spaces. Using car parks is often preferable to parking on the street as many roads are reserved for resident permit holders only. Car parks may also allow parking for longer periods (Clayton et al., 2014).

In the coming years, we will see vehicle-toeverything vehicles (V2X) interacting with its environment using relevant technologies. In 2040, it is estimated that $40 \%$ of the journeys will be made by autonomous vehicles (Bagloee et al., 2016). In order to encourage public transportation and increase mobility, fixed payment options should be applied in various free travel and unlimited use of public transportation for certain periods.

All these practices should be implemented to ensure effective management of limited resources and to develop sustainable transportation policies by increasing mobility.

\subsection{Mobility as a Service (MaAS) and Related Integrated Management}

Mobility as a Service (MaAS) is the most significant concept considered as a prominent transportation service component for leading cities to invest in $R \& D$ in digital transformation. MaAS has only been conceptually identified in the literature, and is suggested to be developed as final products or services. Mobility as a Service is a service concept to reach the intelligent transportation system (Yang and Lee, 2019). Its purpose is to connect and bring together service modes on a single platform to improve the travel experience.

Passengers using MaAS only pay for the entire trip at once, and the maximum benefit is achieved for the optimization of the service. The resources of the service operators are integrated into the entire transportation system.

In order for cities to overcome the transport challenges they face, they need to increase mobility. As the mobility increases, the efficiency of transportation services increases. Advanced modern technology tools (artificial intelligence, internet of things, emotional intelligence technology, big data and analytics, etc.) are widely used in business models developed to increase mobility.

Sharing economy, multimodal and intermodal transportation segment are prominent issues to increase mobility. In the transition from Mobility 3.0 to Mobility 4.0 , cities need to plan resources for this infrastructure return, on the other hand, it is possible to obtain the maximum economic benefit from business model opportunities. 
It is recommended that cities transform their transport management infrastructure according to the MaAS system to offer an economic advantage. This transformation is enabled by integrated service management. Figure 4 provides a management transformation proposal that will ensure common planning and interactive management.

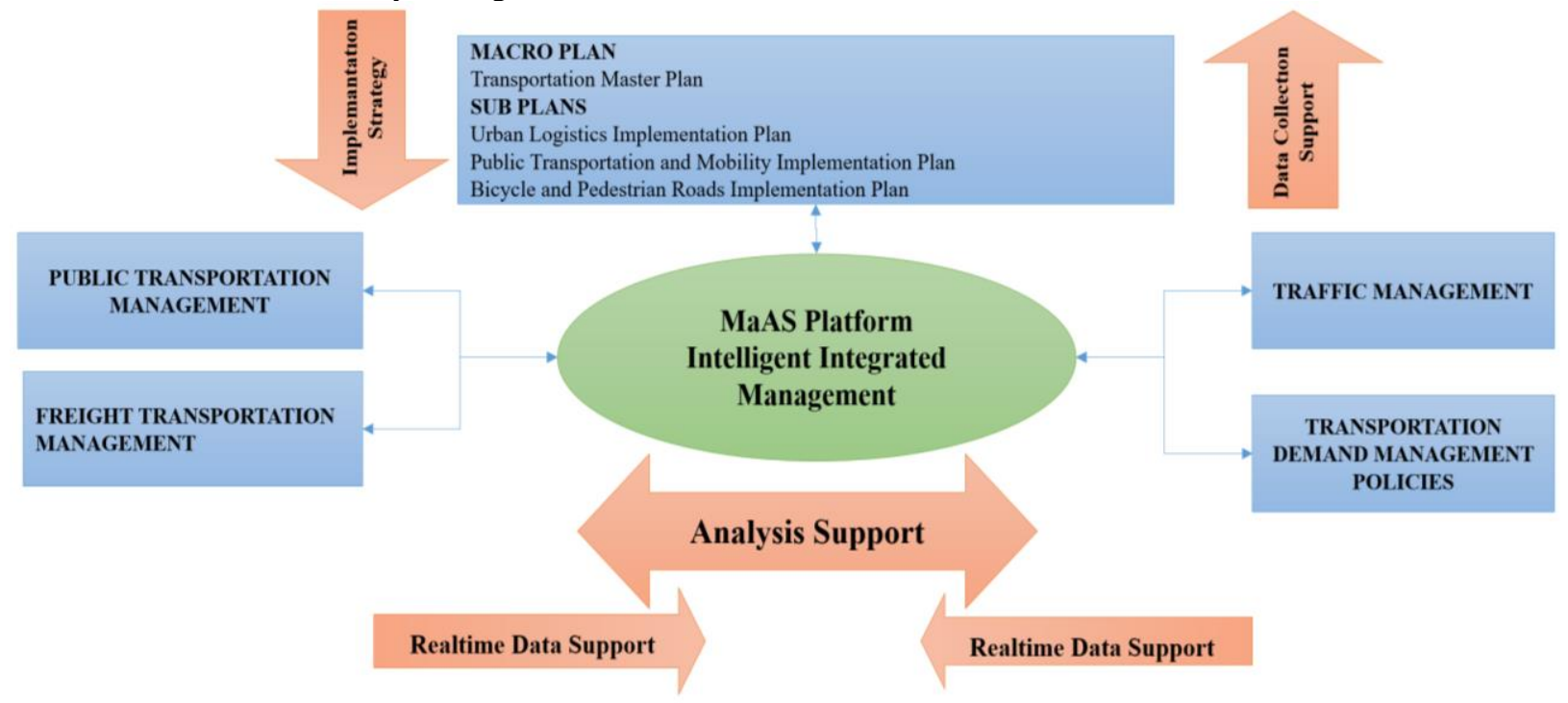

Figure 4. Proposed Frame for MaAS Platform and Integrated Management

A common MaAS platform to be established according to the proposed framework must be systems that take implementation strategies from the transportation master plan and sub-plans and provide real-time data support to these plans. It should ensure that the major components of transport management are integrated together to share data and use common infrastructure. The level of smartness required by each transport component should be determined.

The common MaAS Platform is possible with endto-end encrypted data sharing and data security using block chain technology. It is essential to ensure the security of commercial and personal data and service integration. Intelligence level should be determined for each transportation component. Investment decisions for the management of services and the priority order of these investments should be determined with a strategically focused approach specific to cities.

\subsection{Level of Smartness in Transportation Systems}

In order to express the transition from "Traditional" to "Intelligent" for urban mobility, a 4-tier operational management level is defined as part of this study. Figure 5 shows a comprehensive approach, a scale, to evaluate operational management of transport transition process in which the working level of operational management is determined. This scale is developed within the scope of the study. For instance, the transition from "Digital" to "Intelligent" has been defined as a concept working in line with the transition from Mobility 3.0 to Mobility 4.0.

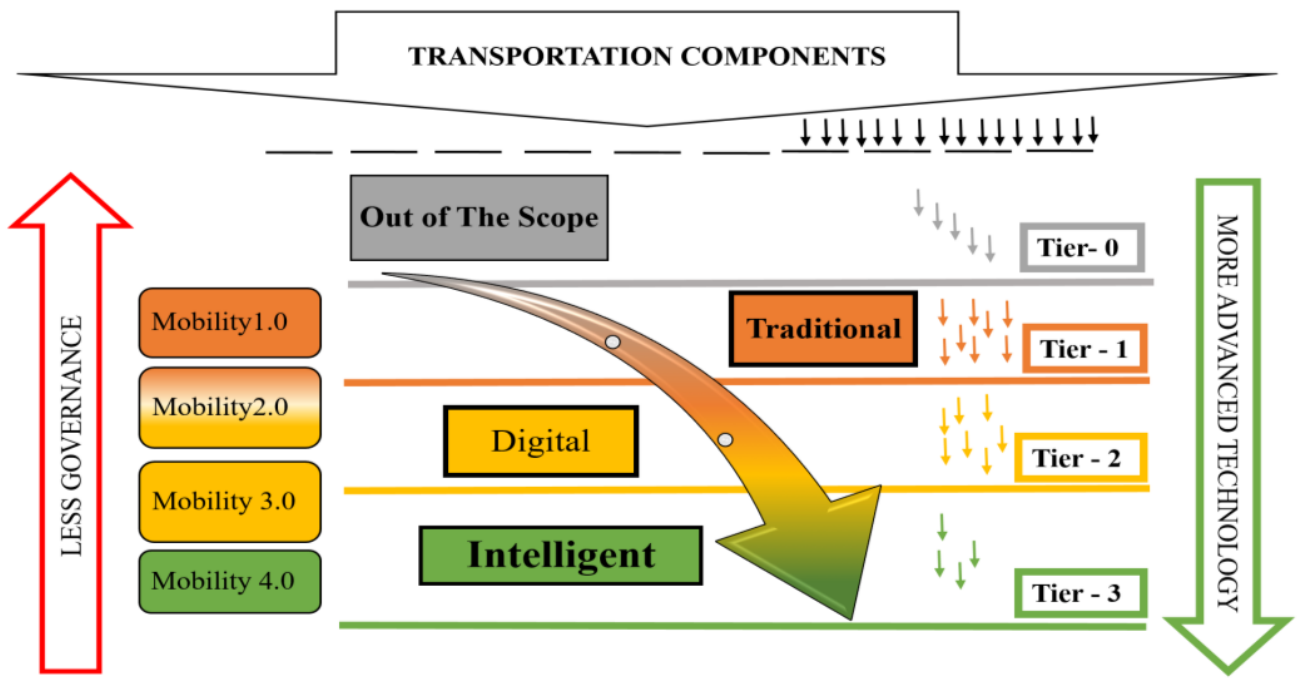

Figure 5. Services operated and managed levels of tiers 
The 4-tier model developed to identify the smartness level of a transportation system is used in the assessment of the digital transformation of a city. The assessment should be made for each component of the city's integrated transport system. The smartness of a component is defined in 4 levels as seen in Figure 5 and is determined following the expert evaluation.

"Tier-0" is the lowest level and defined as "Out of the Scope", which means that there is no defined smart service in the management of the transportation component. This transportation service may not be available in the city before. For example, for a city without a rail system, rail system line optimization is not required.

The second level, "Tier-1", is defined as "Traditional" referring that there is no need for public investment in the management of the service. The current level of smartness is considered to be sufficient for the management of the service. The services identified at this smartness level usually use digital services provided by the private sector mobile services.

"Tier-2" level is defined as "Digital" indicating that there is a need to develop a web- or mobile-based digital service to execute the service. The smartness in the digital transportation system is expected to include the sample capabilities listed below.

$\checkmark$ It is expected to have a real-time and shared traffic information system (with mobile and web support).

$\checkmark$ Public transport should provide route inquiry and travel planning services.

$\checkmark$ Electronic ticket application is expected to be included, where subscription initiation and contactless payments should be available.

$\checkmark$ Services such as remote payment, debt inquiry and registration capabilities for all transportation components should be available.

$\checkmark$ An integrated payment system in multimodal public transport should be provided.

The final level, "Tier-3", is defined and named as "Intelligent". This means that a cyber-physical system should be in place for the execution of the service. Systems empowered with artificial intelligence (AI), using big data and internet of things (IoT) technology infrastructure may be required. The integrated intelligent transportation system is expected to avail the following capabilities as listed below.

$\checkmark$ Transport and traffic systems is monitored in real time and enhanced with artificial intelligence.

$\checkmark$ A real-time information system to collect, process and analyse the current/ongoing transport and traffic with big data and data analytics capabilities.

$\checkmark$ Coordination of transport and traffic-related incidents, information sharing with stakeholders and incident management services.

$\checkmark$ Providing real-time travel advice to public transport users.

$\checkmark$ Analyse and schedule the impact of planned construction and maintenance activities on transport and traffic.

\subsection{Process Flow Chart of the Proposed Approach}

The model offers components to be used as decisionsupport systems for decision makers and also makes suggestions for determining the level of smartness based on the decision maker's preferences and decisions. A decision maker is allowed to choose the indexes as the set of preferences among the predetermined indexes, then determines the working values. At this stage, the model is structured in accordance with the choices of the decision makers. The level of smartness of each identified transportation component is identified based on expert views and index values. Once the smartness level is identified, the targeted digitalization rates of the city under consideration are determined. Finally, the model makes a priority ranking with strategy-focused assessment. The decision maker can decide on the transformation of the transportation management components with the strategy opted among the predetermined ones. The model can be rerun to generate different configurations to diversify offered solutions. The process flow chart of the proposed approach is shown in Figure 6. 


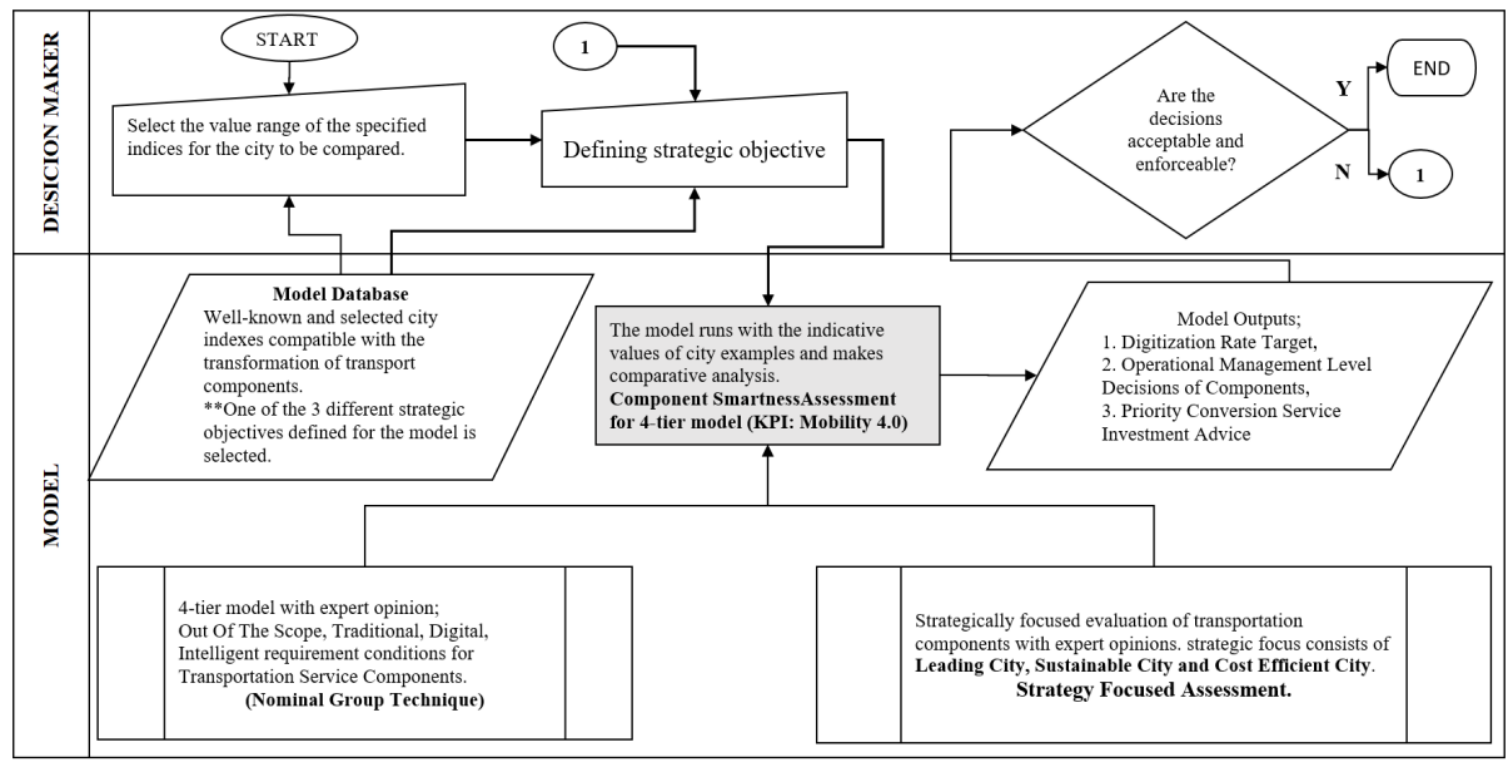

Figure 6. The process flow chart of the proposed approach

The model outputs 3 results. The first result is the proportional target suggested for the operational management smartness levels of transport services (out of the scope, traditional, digital and intelligent) for the city under-consideration. The second result is the digitalisation suggestion for the operational service level of each transport service component. The last one, it is the prioritization of transport components to be transformed by comparative strategic focus assessment. If the model outputs are suitable for the decision maker, the results are used as a digital transformation goal. Otherwise, the decision maker can re-run the system with different configuration options for a new assessment with variations and indexes.

Strategic priorities suitable for the conditions of the cities should be determined together with the model setup. Strategic focused assessment is used for prioritizing the components whose smartness level is determined. As a result of the model, investment priority, among the components evaluated at the same level of smartness, may change depending on the strategy. The decision maker decides on the digitization investment priority ranking by choosing the appropriate strategy.

The scope of this paper is emphasised on identifying the smartness level of transportation systems of smart cities using expert views. The experts, whose views were consulted in this study, have been selected among those who work in the public and private sectors and have expertise in transport management in various capacities including engineers, specialists and junior/ senior managers, who are actively on duty either in academia or in industry. It is important to note that the expert-views have been elicited from twenty-one experts whilst the development of conceptual and reference models.

In the expert opinion method, the nominal group technique was used. As a first step, the factors connected with the digitisation of transport services have been identified, indicators of smart cities in the literature that could express these factors have been selected, and then the experts were asked to suggest sufficient conditions for the smartness levels proposed within the model. After identifying component smartness level, a comparative assessment as to dedicate strategic investment priority was performed using R\&D product development approach. A comparative assessment of the components for which the level of smartness was identified as a strategic priority with Mobility 4.0 components was conducted as a sample.

\section{A Case Study}

The proposed four-level model approach is based on the concept of Mobility 4.0 to determine the level of smartness. The level of smartness, which is considered as traditional, means that the services in the Mobility 2.0 stages are widely used for the city. The meaning of smartness level evaluated "digital" refers to Mobility 3.0 and Mobility 4.0 transition period. It should be understood that cities that determine urban transportation services at the level of smartness "intelligence" are managed with the concept of Mobility 4.0. Figure 7 illustrates how the model will measure the level of smartness of cities with different capacities. 


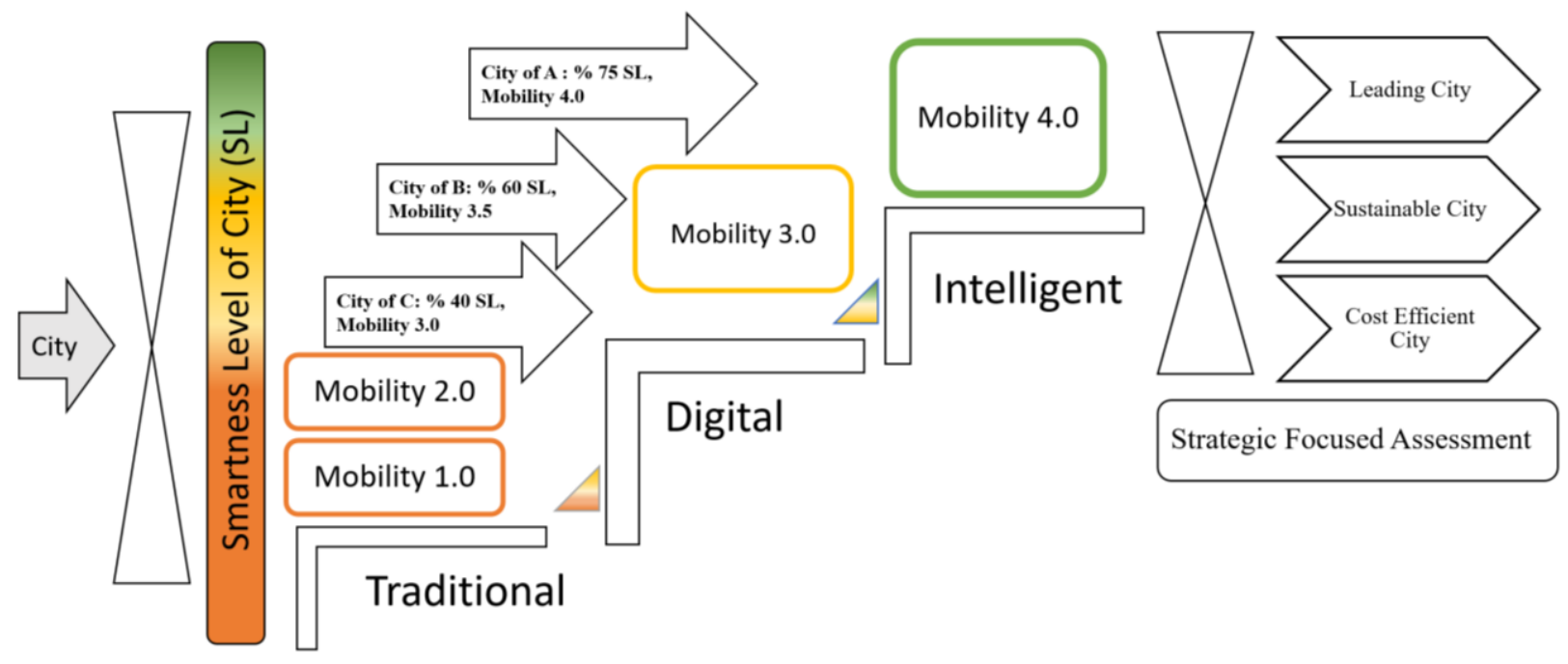

Determination of Smartness Level of City (SL)

Figure 7. The level of smartness of cities with different capacities

It is assumed that the selected sample cities "A", "B" and "C" will set targets at various levels of smartness in the model assessment. These results can be achieved by assessing the smartness levels of each of the transport components of these cities. With the parameters of the index to be chosen and the opinions of experts, the level of intelligence of each transport component is determined by the proposed framework model. When some examples of transport components are assessed using the model, the level of smartness indicated in Figure 8 is suggested for selected cities.

\section{Smartness Level of Transportation Components for the Selected Cities}
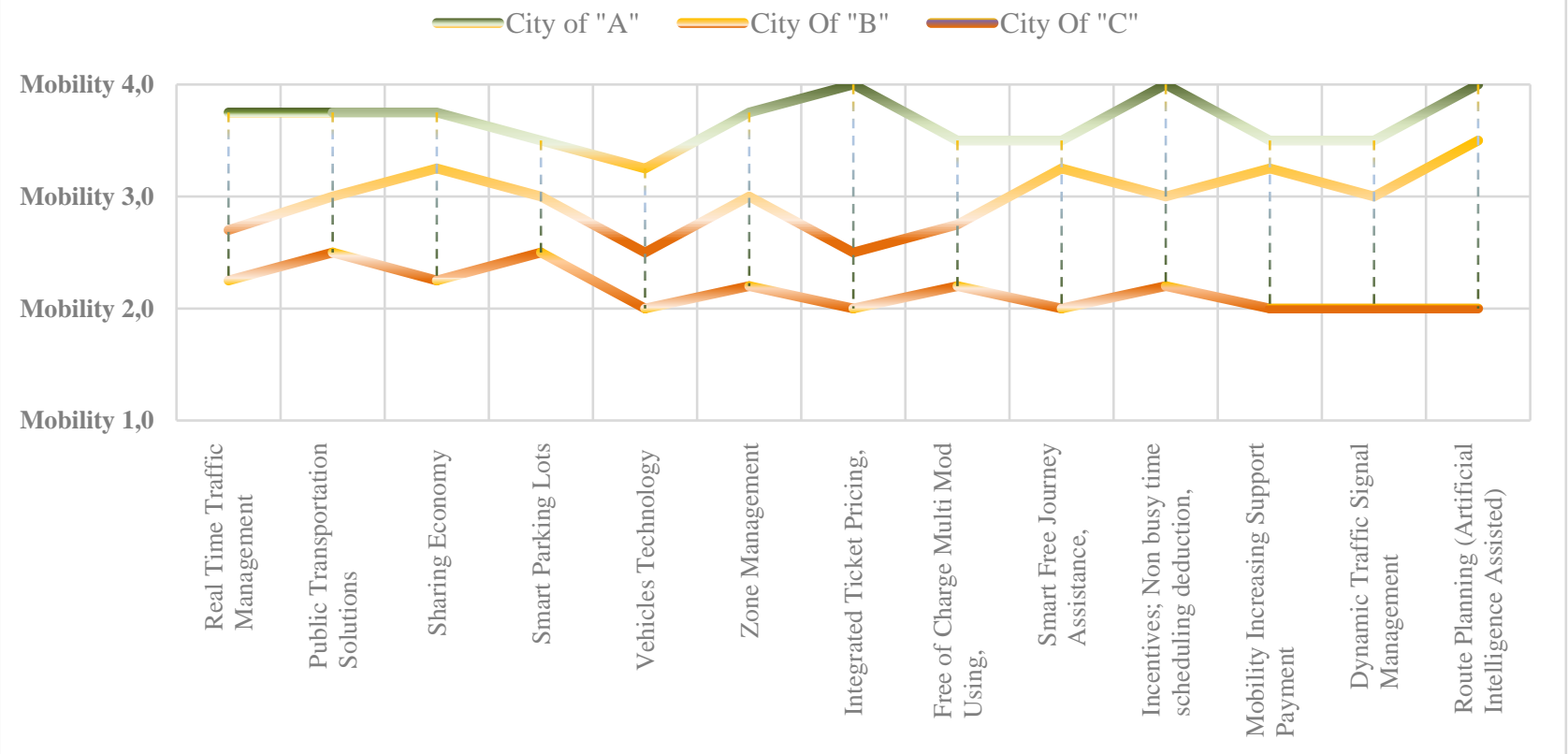

Figure 8. The level of smartness of cities with different capacities

With the conditions indicated, it is recommended by the model that City A serves at $75 \%$ smartness (SL) and Mobility 4.0 level. This means that investing in the Cyber Physical System (CPS) has to be prioritised for these transport components. However, there seems to be a need for Mobility 4.0 services in the management of certain transportation components for City B. A detailed review of these services is recommended. 
Once the smartness rate and the digitalization proposals for the transportation components of cities under consideration, the transportation components to invest in are required a strategically focused assessment. A strategically focused prioritization study is carried out among the components by using multiple decisionmaking techniques. In this study, 3 different strategic focuses are determined for decision makers to choose one among; "Leading City", "Sustainable City" and "Cost Efficient City ". The preferred strategic focus is used to set investment priorities for digitalization.

"Leading City" imposes a strategic priority that prioritizes citizens' expectations and is likely to have a disruptive impact on existing transport operators. It is a strategy that only economically powerful cities should choose. Extra investment is required to change or remove existing licenses and authorizations. By creating research and development (R\&D) funds, opportunities are provided for new innovative projects. It is recommended to select cities that lead digitalization with leading city characteristics. Examples are more common in developed economies. Cities such as London, Paris, New York, Tokyo, and Seoul are examples of this category. The characteristic feature of this strategy is the R\&D investment towards digital transformation.
"Sustainable City" is a strategic approach that aims to implement digitalization with the effective management of existing resources. It focuses on changing citizen habits in solving problems in the city. Pedestrian-oriented solutions such as parking lot management, cycling, and extending pedestrian areas are prioritized. In general, cities that choose this strategy, with strong infrastructure and human resources, follow leading cities. Cities such as Amsterdam, Barcelona, Copenhagen, Milan, Rome and Glasgow can be cited as examples.

"Cost Efficient City" offers suitable strategies for cities that expect income from digital transformation. Cities that choose this strategy need to invest in incomegenerating and relatively low infrastructure. Long-term financing of digital transformation is recommended with authorization and licensing revenues after the first stage of transformation. However, this strategic approach is not suitable for leading cities. Digital transformation applications should be implemented as the adaptation of successful practices that have been tried and accepted in other cities. Cities such as Istanbul, Moscow and Beijing can be given as examples

In Figure 9, the assessment of R\&D investments required for the development of MaAS by type of strategy is presented in terms of main transport components.

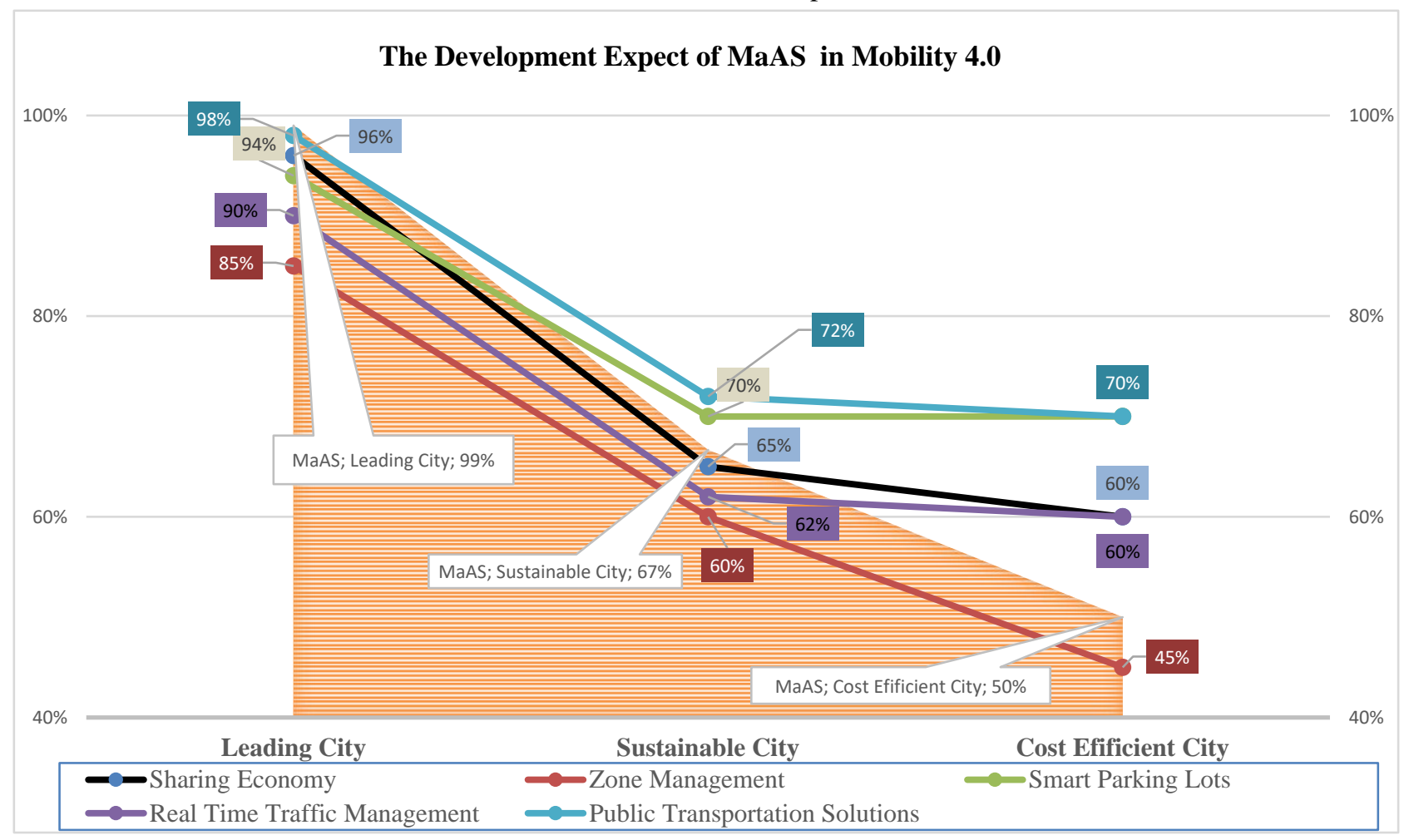

Figure 9. Strategic assessment for MaAS development with main component

It is expected that MaAS would evolve as part of the Mobility 4.0 components. However, according to expert assessments, cities should target different levels of development according to their strategic priorities for the digitization goal, each of which requires ICT and R\&D investment. As seen from Figure 9, the simultaneous execution of the development of all 
components can be determined as a target for a city which is a leading city.

Of course, it should be known that cities make decisions together with all stakeholders. According to experts, the reason for delaying the full commissioning of a technologically advanced service such as "zone management" is commercial and social concerns. Figure 9 shows us that investment priorities and digitization rates have changed strategically effectively when some of the Mobility 4.0 services, which have advanced technological infrastructure, are considered together with MaAS, which is still at the conceptual stage

"Intelligent" cities, such as City "A", with a goal of digitalization at the Mobility 4.0 level and targeting over $75 \%$ smartness, need to invest in digitization and R\&D. These cities are considered to be leading cities. All transport components are assumed to be holistically simultaneous conversion goals. The "Leading City" strategic focus would be a suitable choice for these cities. They are expected to make the R\&D investments needed for MaAS. These cities should have smartness transportation management targets in excess of $75 \%$.

It is recommended that "Digital" cities such as City "B" with a digitalization target above Mobility 3.5 and aiming for over $60 \%$ smartness choose the "Sustainable City" strategy. In these cities, the primary transport component transformation are Public transport management and real-time traffic management components. Once prototype applications are developed for MaAS, these cities are expected to develop various innovative services with pilot cases.

It is suitable for cities that transition from traditional systems to digital systems such as city "C", which has a digitalization target above Mobility 3.0 and aims for over $40 \%$ smartness, to carry out digitalization with the "Cost Efficient City" strategy. The transportation components planned for primary transformation in these cities are low-cost and high income-generating features. Parking areas management, real-time traffic management is the primary conversion component. $\mathrm{MaAS}$ is a high-potential conceptual approach to complement its development as a service inspired of cloud solutions. In the next few years, it would evolve with the R\&D investments of leading cities and the pilot cases that sustainable cities will bring in diversity. Mature MaAS services will be used by cities in this category without investing in $\mathrm{R} \& \mathrm{D}$.

The decision maker makes the prioritization assessment of the transportation components by choosing the appropriate one from the strategy-based evaluation made by the experts for the province it evaluates.

\section{Conclusions}

The assessment of digitisation is a present and new field of study in the literature. There are some studies that compare the digitization rates of cities with maturity models in smart city concepts. Existing research does not include comprehensive models to define a vision of digitization for cities. This study was developed with the idea that the city is unique and needs its own digitization objectives.

In this article, the concepts of determining cityspecific digitalization targets covers Mobility 4.0 and suggest smartness levels, according to the its components and determining investment priorities with a strategic assessment for MaAS Concept Development are presented.

Literature review confirms how difficult is to define the transformation situation of smart cities with a universal system. Priorities, targets and visions identified for cities play very important role in this process. Studies conducted within the scope of digital transformation of transportation services are compatible with "Mobility 4.0" concepts in literature research. Providing services with integrated and interactive management in this concept constitutes the future perspective of transportation services. The maturity levels of services transformed by digitalization vary. A strategic approach is necessary to assess mature services, prototype services and services that are still in conceptual stage. MaAS is a major powerful conceptual component of digitalization relevant to Mobility 4.0. It is recommended that cities assess MaAS transformation in terms of transport components with a well-known strategy to seize opportunities. This study has been conducted by evaluating that known index values can be used in the digital transformation of transportation services. The potential development of the MaAS concept in the digitalization process is evaluated using the developed 4-tier smartness level approach. It also provides proposals for strategic ranking of priority investments with an R\&D approach. The approach can be used as a roadmap for cities that want to transform Mobility 4.0 and want to define a MaAS strategy.

\section{Acknowledgment}

The Scientific and Technological Research Council of Turkey (TÜBİTAK) Science Fellowship and Grant Programmes Department supported this study, which produce from PhD Study of Hakan INAC (Application Number: 1059B141900373).

\section{References}

Akpınar, M., 2019. Smart City Applications in Digital Age: State-Of-Art Review and Critique. Journal of Information Systems and Management Research, 1(1), 37(42).

Albino, V., Berardi, U., Dangelico, R. M. 2015. Smart cities: Definitions, dimensions, performance, and initiatives. Journal of urban technology, 22, 3-21.

Angelidou, M., Psaltoglou, A., Komninos, N., Kakderi, C., Tsarchopoulos, P., Panori, A. 2018. Enhancing sustainable urban development through smart city applications. Journal of Science and Technology Policy Management. 
Anttiroiko, A.V., Valkama, P., Bailey, S. J. 2014. Smart cities in the new service economy: building platforms for smart services. AI \& society, 29, 323-334.

Bagloee, S. A., Tavana, M., Asadi, M., Oliver, T. 2016. Autonomous vehicles: challenges, opportunities, and future implications for transportation policies. Journal of modern transportation, 24, 284-303.

Bello, J. P., Silva, C., Nov, O., Dubois, R. L., Arora, A., Salamon, J., Mydlarz, C., Doraiswamy, H. 2019. Sonyc: A system for monitoring, analyzing, and mitigating urban noise pollution. Communications of the ACM, 62, 68-77.

Butler, L., Yigitcanlar, T., Paz, A. 2020. Barriers and risks of Mobility-as-a-Service (MaaS) adoption in cities: A systematic review of the literature. Cities, 103036.

Clayton, W., Ben-Elia, E., Parkhurst, G., Ricci, M. 2014. Where to park? A behavioural comparison of bus Park and Ride and city centre car park usage in Bath, UK. Journal of Transport Geography, 36, 124-133.

Colvile, R., Hutchinson, E. J., Mindell, J. \& Warren, R. 2001. The transport sector as a source of air pollution. Atmospheric environment, 35, 1537-1565.

Cottrill, C. D. 2020. MaaS surveillance: Privacy considerations in mobility as a service. Transportation Research Part A: Policy and Practice, $131,50-57$

Crainic, T. G., Ricciardi, N., Storchi, G. 2009. Models for evaluating and planning city logistics systems. Transportation science, 43, 432-454.

Fagnant, D. J., Kockelman, K. M. 2014. The travel and environmental implications of shared autonomous vehicles, using agent-based model scenarios. Transportation Research Part C: Emerging Technologies, 40, 1-13.

Foltýnová, H. B., Attard, M., Melo, S. 2018. Topical collection on the role of planning towards sustainable urban mobility. Springer.

Giffinger, R., Fertner, C., Kramar, H., Meijers, E. 2007. Cityranking of European medium-sized cities. Cent. Reg. Sci. Vienna UT, 1-12.

Greenblatt, J. B., Shaheen, S. 2015. Automated Vehicles, OnDemand Mobility, and Environmental Impacts. Current Sustainable/Renewable Energy Reports, 2, 74-81.

Halliday, S. 2013. Underground to everywhere: London's underground railway in the life of the capital, The History Press, ISBN 9780752495514.

Hellinger, A., Seeger, H. 2011. Cyber-Physical Systems. Driving force for innovation in mobility, health, energy and production. Acatech Position Paper, National Academy of Science and Engineering, 1.

İnaç, H., Dönmez, C. 2018. Evaluation of Value Capture Strategies for Public Private Partnership Projects in Railway System Projects to be Built in Istanbul City, International Journal of Advances in Engineering and Pure Sciences, 30(3), 286-298. DOI: 10.7240/marufbd.396649.

Kaparias, I., Bell, M., Tomassini, M. 2011. Key performance indicators for traffic management and intelligent transport systems. ISIS, 14.

Kemeny, T., Storper, M. 2015. Is specialization good for regional economic development? Regional Studies, 49, 1003-1018

Khayyat, N. T., Lee, J.D. 2015. A measure of technological capabilities for developing countries. Technological Forecasting and Social Change, 92, 210-223.
Klingenberg, C., Antunes, J. 2017. Industry 4.0: what makes it a revolution. EurOMA 2017, 1-11.

Kumar, P., Morawska, L., Martani, C., Biskos, G., Neophytou, M., Di Sabatino, S., Bell, M., Norford, L., Britter, R. 2015. The rise of low-cost sensing for managing air pollution in cities. Environment international, 75, 199-205.

Lee, J., Bagheri, B., Kao, H.-A. 2015. A cyber-physical systems architecture for industry 4.0-based manufacturing systems. Manufacturing letters, 3, 18-23.

Lytras, M. D., Visvizi, A. 2018. Who uses smart city services and what to make of it: Toward interdisciplinary smart cities research. Sustainability, 10, 1998.

Ma, X., Xue, H. 2020. Intelligent smart city parking facility layout optimization based on intelligent IoT analysis. Computer Communications, 153, 145-151.

Manville, C., Cochrane, G., Cave, J., Millard, J., Pederson, J. K., Thaarup, R. K., Liebe, A., Wissner, M., Massink, R., Kotterink, B. 2014. Mapping smart cities in the EU.

Metz, D. 2018. Tackling urban traffic congestion: The experience of London, Stockholm and Singapore. Case Studies on Transport Policy, 6, 494-498.

Morse, L.C., Babcock, D.L., Murthy, M. 2014. Managing engineering and technology, Pearson.

Mouchili, M. N., Aljawarneh, S., Tchouati, W. Smart city data analysis. Proceedings of the First International Conference on Data Science, E-learning and Information Systems, 2018. 1-6.

Müller, I. S., Liedtke, G. Understanding structural barriers of innovations towards sustainable transportation.

Nagy, D.K. 2016. City location and economic development. Princeton University, mimeograph.

Ngo, H. Q.T., Nguyen, T.P., Nguyen, H., 2019. H. Hardware Design for Intelligent IoT Approach to Optimize Parking Slots. 2019 International Conference on Advanced Computing and Applications (ACOMP), IEEE, 171-175.

Pringle, P., 2011. AdaptME toolkit: Adaptation monitoring and evaluation. Oxford, UK: UKCIP. accessed 29, 03-21.

Razaghi, M., Finger, M. 2018. Smart governance for smart cities. Proceedings of the IEEE, 106, 680-689.

Redman, L., Friman, M., Gärling, T., Hartig, T. 2013. Quality attributes of public transport that attract car users: A research review. Transport policy, 25, 119-127.

Sharifi, A. 2020. A typology of smart city assessment tools and indicator sets. Sustainable cities and society, 53, 101936.

Smith, G., Sochor, J., Karlsson, I. M. 2018. Mobility as a Service: Development scenarios and implications for public transport. Research in Transportation Economics, 69, 592-599.

Sochor, J., Strömberg, H., Karlsson, I. M. 2015. Implementing mobility as a service: challenges in integrating user, commercial, and societal perspectives. Transportation research record, 2536, 1-9.

Şentürk, İ., Coulıbaly, S., 2020. Mobile Data Collection in Smart City Applications: The Impact of Precedencebased Route Planning on Data Latency. Journal of Innovative Science and Engineering, 4 (1), 22-34. DOI: $10.38088 /$ jise. 713809 .

Tay, K.C., Supangkat, S. H., CORNELIUS, G. \& ARMAN, A. A. The SMART initiative and the Garuda smart city framework for the development of smart cities. 
2018 International Conference on ICT for Smart Society (ICISS), 2018. IEEE, 1-10.

Wolff, H., Perry, L. 2010. Policy monitor: trends in clean air legislation in Europe: particulate matter and low emission zones. Review of Environmental Economics and Policy, 4, 293-308.

Yaman, O., Bayğın, M., 2020. UHF-RFID, Smart Cargo Management, Real Time Tracking. Journal of Intelligent Systems: Theory and Applications, 3 (2), 38-45. DOI: $10.38016 /$ jista.762685

Yang, W., Lee, S.P. 2019. Service Model Research of Bicyclesharing based on Mobility-as-a-Service (MaaS). Journal of Service Research and Studies, 9, 19-40. 